\title{
Projeto Zaptlogs: as tecnologias educacionais informatizadas no trabalho de educadores
}

\author{
Suzana de Souza Gutierrez *
}

\begin{abstract}
Resumo: O zaptlogs é um projeto de pesquisa sobre a inserção das tecnologias educacionais informatizadas no trabalho de educadores que cooperam em comunidades de pesquisadores. Utiliza os weblogs, como ambiente principal de interação, por considerar que este formato de publicação na rede mundial de computadores apresenta características que o tornam um suporte ideal para o desenvolvimento de processos cooperativos com autoria e autonomia. Este artigo tem como objetivo apresentar o projeto zaptlogs, descrevendo sua concepção teórica, sua criação e desenvolvimento até o presente momento.
\end{abstract}

Palavras-chaves: educação, formação de professores, internet, tecnologia, weblogs.

Abstract: Zaptlogs is a research project on the insertion of educational technologies in the work of educators who cooperate in communities of researchers. It uses weblogs, as main environment of interaction, for considering that this publication format in the world wide web presents characteristics that make it an ideal support for the development of cooperative processes with authorship and autonomy. This article has as objective to present the project zaptlogs, describing its theoretical conception, its creation and development until the present moment.

Key-words: education, teacher education, internet, technology, weblogs.

\section{Introdução}

Decorre cada vez menos tempo entre a criação de uma tecnologia, sua disponibilização e a disseminação de sua utilização na sociedade. Se compararmos a evolução de tecnologias como telefone fixo e a televisão veremos esta aceleração.

Em relação às tecnologias ligadas à informática, a questão não é se e sim quando um terminal de computador vai fazer parte do cotidiano de cada cidadão do planeta.

\footnotetext{
Professora e Engenheira, Especialista em Metodologia do Ensino, Mestranda em Educação PPGEdu/UFRGS. Professora do Colégio Militar de Porto Alegre. Pesquisadora do TRAMSE/UFRGS. ssguti@terra.com.br 
Esta tendência vem sendo confirmada pela velocidade com que as tecnologias ligadas à informática estão tomando espaço em todos os setores.

Muitos contrapõem a esta afirmação o fato de que o acesso ao computador e a internet tem custo elevado e, portanto, é privilégio de poucos. Concordo, porém esta afirmação não contradiz o fato de que em breve os terminais computadorizados farão parte do cotidiano de todos. Ao contrário, é até uma postura ingênua nesse sentido. Não contradiz na medida em que as tecnologias informáticas é que alcançam as pessoas e não o oposto. Alcançam através do uso crescente de cartões eletrônicos diversos, de novos instrumentos de trabalho, de urna eletrônica nas eleições, de caixas eletrônicos, etc. Além disso, não é a tecnologia que se desenvolve e expande de moto próprio, antes é o nosso velho conhecido capital, no seu interminável acelerar em busca de melhores caminhos de circulação e de novos mercados.

Em relação à educação, o papel das tecnologias informatizadas é um assunto relativamente recente e que tem motivado acirrados debates. Porém, existe o consenso de que a tecnologia terá cada vez mais presença na sociedade contemporânea e incertezas e preocupações se associam a este pressuposto.

A meu ver, a principal contradição é a de que as tecnologias educacionais informatizadas (TEI) podem ser as tecnologias da educação (AXT, 2000) no sentido em que são frutos de um projeto de sociedade e de educação dirigido pela e para a participação coerente e crítica de todos. Ou podem ser tecnologias na educação, na medida que forem a objetivação das idéias e do projeto de mundo de uma classe dominante. Nesse sentido, se não nos apressarmos em construir as tecnologias $d a$ educação acabaremos tendo que aceitar algumas tecnologias na educação.

De igual modo, a velocidade e a dimensão com que as transformações vêm ocorrendo aumentam a nossa insegurança frente à complexidade de todo este processo. Vivemos a crise das certezas num contexto de crescente injustiça social e de ameaças à própria sobrevivência do planeta. Papert (1985, p. 12) é otimista quando diz que: "Não se trata aqui de nos perguntarmos pessimistamente o que o desenvolvimento tecnológico fará conosco e sim pensarmos o que nós faremos com ele".

$\mathrm{Na}$ realidade, este posicionamento aparentemente assertivo deixa entrever a suposição de que estaremos lidando com um desenvolvimento tecnológico já de antemão dado e que, neste contexto, apenas podemos decidir o que melhor fazer com ele. Existe, porém, este determinismo? Assim sendo, estará em nossas mãos decidir? 
Penso que as variáveis deste processo não se resumem a nós e ao desenvolvimento tecnológico. O desenvolvimento tecnológico não é por si só o desencadeador das mudanças. Ele próprio é gerado, fruto da prática social assim como toda a realidade. Contudo, este processo tem contradições e é tornado opaco pela ideologia, assumindo a roupagem do pensamento dominante.

Considero que os rumos que o desenvolvimento tecnológico vêm tomando de forma geral e, também, na educação não podem ficar fora das mãos dos educadores, da sua reflexão crítica e da sua possibilidade de intervenção. Para isso, torna-se vital a investigação, a ampliação e a troca de conhecimentos nesta área por parte dos educadores e das instituições educacionais. Sobretudo, investigações que se relacionem com a inserção das TEI no trabalho dos educadores e que considerem todos os aspectos que circundam este tema.

Todas as questões referentes ao uso da tecnologia, a sua criação, seu papel no cotidiano das pessoas, os espaços e interações que elas criam, as relações que emergem nestes espaços, são questões importantes e urgentes para a humanidade. A disponibilidade deste viver em rede, pelos desdobramentos múltiplos e profundos que possui, requer que nos apropriemos deste conhecimento para podermos participar de forma consciente, crítica e eficiente da construção das relações que emergem nestes espaços. 


\section{A blogosfera - um novo paradigma de publicações na internet}

Weblog ${ }^{1}$ ou, simplesmente, blog, como é popularmente chamado, é um tipo especial de página publicada na internet. Sua origem confunde-se com nascimento da própria rede mundial de computadores, mas, como fenômeno específico, é recente.

Existem várias diferenças entre os weblogs e os sites $^{2}$ que normalmente encontramos na rede. Em primeiro lugar, os weblogs são extremamente dinâmicos e mostram todo o conteúdo mais recente na primeira página, sob a forma de textos curtos, os posts, dispostos em ordem cronológica reversa. Apresentam poucas subdivisões internas, quase sempre restritas a links para os arquivos, que guardam o conteúdo mais antigo, e para alguma página que descreve o site e seu autor. Apresentam, também uma quantidade grande de links para outras páginas, geralmente outros weblogs.

Outra característica é a facilidade com que podem ser criados, editados e publicados, com pouquíssimos conhecimentos técnicos. Na rede, disponíveis mediante um simples cadastro, encontram-se ferramentas, em versões gratuitas ou não, que realizam a codificação do weblog, sua hospedagem e publicação.

Um dos mais antigos weblogs que se conhece foi o $\underline{\text { News }}^{3}$, criado em 1996 por David Winer como parte do site 24 Hour Democracy. Hoje chama-se $\underline{\text { Scripting News e }}$ continua publicando notícias, comentários e discussões sobre a www, aplicativos, programação, etc. De 1999 em diante, com o advento dos servidores de weblog como o

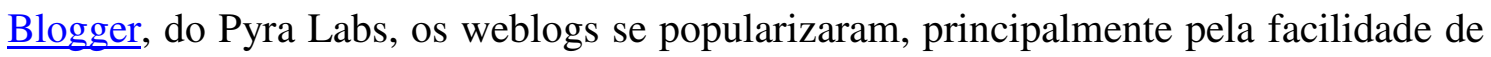
sua criação e manutenção proporcionadas pelas ferramentas destes servidores. Em 2002, seu número era estimado em meio milhão. Com dados de junho de 2003, a Blogcount (2003) estima que, hoje, eles sejam o triplo, mais de um milhão e meio.

Atualmente, toda uma criatividade gira em torno dos weblogs. A cada dia surgem novos aplicativos, novas ferramentas de edição, servidores, indexadores. Entre estes, podemos citar o software brasileiro Bloggar, de Marcelo Cabral, um editor de html que agrega uma série de recursos de edição. Através de comandos simples, semelhantes aos dos editores de texto, permite a formatação, a postagem e a publicação do weblog, sem que seja necessário entrar no servidor.

Os weblogs reúnem-se em verdadeiras comunidades onde a troca de informações é intensa. Sistemas de comentários, como o do Blogger.br, adicionados a página, permitem que cada post possa ser comentado pelos leitores. Esta rede se 
constitui, também, através dos seus links, otimizados pelos serviços chamados trackback, que reúnem as várias referências sobre o mesmo post situadas em weblogs diferentes. Ou o blogrolling, que permite que o link para um blog visitado seja automaticamente anexado ao nosso weblog sem que seja necessário ficar fazendo modificações no código da página.

$\mathrm{O}$ acesso à informação vem sendo facilitado e intensificado por meio da adoção pelos blogueiros ${ }^{4}$ de protocolos como o $\underline{\text { RSS }}$ (Rich Site Sumary ou Real Simple Syndication), que resume o conteúdo mais recente de um site numa forma que possa ser capturada e lida por um aplicativo "agregador de notícias" como o NewsDesk, da Wildgrape. Os blogs rssficados ${ }^{5}$ apresentam um endereço que pode ser copiado e adicionado como novo canal de informações no programa leitor de notícias.

Por outro lado, a blogosfera ao mesmo tempo em que promove a globalização dos contatos, mantém suas raízes com os territórios locais, procurando mapear e situar parceiros próximos, com iniciativas pioneiras como o brasileiro Blogchalk, de Daniel Pádua, que gera um código para ser anexado ao weblog e que, capturado pelos mecanismos de busca, possibilita o encontro de blogueiros. Outro serviço, o GeoUrl, que mapeia as coordenadas de latitude e longitude que integramos ao código de nosso blog ou página e nos possibilita listar todos as páginas situadas num raio de 500 milhas da nossa localização. Existe, também, o The world as a blog, que captura, localiza e publica num enorme mapa a localização do blog e cada post que for adicionado.

Os weblogs vêm se transformando em importantes repositórios de informações, em verdadeiros filtros que avaliam, interpretam e indexam estas informações. Os weblogs são ambientes de construção cooperativa do conhecimento, da criação de comunidades de pesquisadores e, também, uma alternativa à mídia tradicional, uma possibilidade de voz autônoma no ciberespaço.

3. Os weblogs e a educação

Uma das grandes críticas feitas à escola e aos métodos de ensino é a sua ênfase nas informações e na memória. Uma crítica antiga, mas que, apesar do muito que se andou, ainda permanece.

Uma informação é um fato dado, uma interpretação de alguém sobre um fenômeno ou acontecimento. Nesse aspecto, memorizar simplesmente uma informação 
é guardar por um certo tempo um dado que não veio da elaboração do sujeito e que não mobilizou sua cognição na interação dos contextos e relações pertinentes a este assunto. Portanto, não é aprendizagem.

Aprender importa em desconstruir uma informação verificando as suas relações, contexto e significados, comparando, testando e produzindo sentido. Concordo com Bakhtin (2000), onde ele diz que um sentido só existe para outro sentido com o qual coexiste. Um sentido em potencial que se atualiza no encontro com o sentido do outro.

O conhecimento que faz sentido é histórico, é movimento que se refaz sempre. É conhecimento construído socialmente, na ação do indivíduo ao construir sua própria existência. Esta construção social se encontra, também, na teoria de Vygotsky (1989, p.18) onde ele afirma que "o verdadeiro curso do desenvolvimento do pensamento não vai do individual para o socializado, mas do social para o individual". No diálogo com o outro e posteriormente consigo mesmo originam-se as primeiras manifestações da reflexão lógica.

Aprender significa compreender, então compreender situa-se no âmbito da construção do conhecimento (AXT, 2000). Uma construção que não é solitária, pois inclui os conhecimentos anteriores acumulados pela humanidade e o diálogo. A relação dialógica que constrói conhecimento, conforme entende Bakhtin (2000), estabelece-se entre sujeitos de linguagem, entre sujeito e texto e entre textos. Expressa-se nos signos, na linguagem oral e escrita. A digitalização acrescenta a estes meios de construção e expressão do conhecimento toda uma outra formação de signos, outra estrutura de texto, outra dinâmica espaço-temporal e outras relações.

No entanto, a educação em muito ainda mantém o padrão bancário de depósitos e retiradas, se a considerarmos como um todo, isto é, considerarmos a sala de aula, o currículo, a estrutura educacional, os regimentos escolares, a avaliação, etc. A própria inserção das TEI não modifica este quadro e, dependendo do modo como acontecer este processo, pode torná-lo pior.

Independentemente disso, alternativas diferenciadas para o ato educativo, como as abordagens construtivistas, o ensino-pesquisa, a inclusão das TEI, se configuram em ações que pressionam as estruturas educacionais no sentido de sua transformação.

O ensino como pesquisa é aquele onde o educador, ao mesmo tempo em que ensina, aprende, questiona a realidade de sua prática, da escola e da comunidade escolar e, onde o educando, ao mesmo tempo em que aprende, busca respostas às suas 
indagações e, portanto, ensina. Deste modo, o ensino-pesquisa é da ordem da formação do educador.

Em relação ao ensino-pesquisa concordo com a proposta de Triviños (2003) de um ensino baseado na pesquisa-ação crítica. Uma pesquisa-ação construída na semelhança com o trabalho de Paulo Freire. Uma pesquisa, segundo Triviños (2003), dialética e materialista, geradora de novas perspectivas de relacionamento entre professores e alunos; pesquisa que fomenta processos de igualdade intelectual e de liberdade democrática entre os educadores de vários níveis, onde os educandos se inserem como possuidores de conhecimento, com direito à voz e ação; uma modalidade de ensino que desenvolva a cooperação, que promova o trabalho coletivo e que possibilite a constituição de comunidades de pesquisadores.

Como os weblogs podem contribuir para um projeto de ensino-pesquisa?

A meu ver, os weblogs terão cada vez maior importância, especialmente na comunicação e na educação. Atualmente, o formato weblog, vem sendo usado em diversos tipos de publicação. Entre elas, encontram-se páginas pessoais, páginas temáticas, diários de pesquisa, ambiente colaborativo, clipping jornalístico, etc.

De expressão unicamente individual tornou-se uma forma de publicação em coautoria. O contínuo fluxo de informação entre blogueiros deu origem a verdadeiros webring $^{6}$. Estas comunidades de weblogs interligados confirmam a polifonia e a intertextualidade já constatadas em ambientes virtuais.

Por todas estas razões, os weblogs vêm se consolidando como ambientes de construção cooperativa do conhecimento. Neles, o processo de construção ocorre de forma livre e aberta, promovendo o uso social da informação e do conhecimento, colocando estes como direito de todos.

Penso que os weblogs, usados em projetos educacionais, podem desencadear entre os participantes o exercício da expressão criadora escrita, artística, hipertextual. Pela sua estrutura, permitem o exercício do diálogo, da autoria e co-autoria, inclusive na alteração da própria estrutura. Eles possibilitam, também, o retorno à própria produção, a reflexão crítica, a re-interpretação de conceitos e práticas.

Professores e alunos, parceiros de aprendizagem, podem retroagir sobre seu trabalho, revendo etapas e processos, tomando consciência de sua prática. O weblog 
registra de forma dinâmica todo o processo de construção do conhecimento e abre espaço para a pesquisa.

Deste modo, os weblogs contribuem para a consolidação de novos papéis para alunos e professores no processo educativos, com uma atuação menos diretiva destes e mais participante de todos. Uma parceria num processo em que todos ensinam e aprendem. (FREIRE, 2002).

Os weblogs registram todas as fases do projeto, sua criação, seu detalhamento e desenvolvimento até sua finalização. Tornam-se adjuvantes do ensino-pesquisa, facilitam a implementação de projetos inter e transdisciplinares, dando visibilidade, alternativas interativas e suporte a projetos que envolvam a escola como um todo e, até, as famílias e a comunidade. 


\section{O projeto zaptlogs ${ }^{7}$ - concepção geral.}

Em minha proposta de mestrado venho estudando a construção do conhecimento em comunidades de educadores pesquisadores. Investigo a inserção das TEI no trabalho dos educadores, por meio de práticas cooperativas, com ênfase nos aspectos de autonomia e autoria.

Venho abordando estes assuntos de forma diferente das encontradas na maioria das investigações que envolvem as TEI, tanto no ponto de vista da fundamentação teórica e metodológica, quanto nos procedimentos adotados.

Entendo que o conhecimento, a ciência e a tecnologia são patrimônios humanos, que devem ser construídos de modo a vir ao encontro dos interesses da humanidade e ser de livre acesso e utilização por todos. Penso que o educador, no âmbito de seu trabalho, deve ter autonomia, ser autor, livre construtor de suas práticas e dentro destes valores educar seus alunos. Não no sentido de uma independência como "prescindir do outro", ao contrário, no sentido de uma autonomia que parte da consciência da nossa interdependência como seres humanos e que parte do co-operar segundo regras livremente escolhidas na comunidade. Uma autonomia como imperativo ético, diria Paulo Freire (2002). Acredito que é importante o nosso engajamento na luta para manter e conquistar a liberdade e a autoria dentro dos espaços criados pelas TEI. Penso, também, que os estudos que envolvem a prática social humana e seu devir, como processos, precisam ser fundamentados e pensados na dialética de suas contradições, na crítica do seu desenvolvimento.

A inserção das TEI no trabalho de educadores em uma comunidade de pesquisadores, que cria e utiliza um ambiente virtual, é um fenômeno singular específico da inserção das TEI nos espaços educacionais. Este fenômeno, cujo espaçotempo é o ambiente virtual/presencial da comunidade, apresenta tendências contraditórias internas e externas.

Internamente, existem contradições entre: autor-usuário e autonomiadependência em relação à criação/utilização do ambiente virtual e na mobilização de pedagogias. Externamente, o fenômeno como um todo tensiona outras tendências, como, por exemplo, as que deixam de fora dos espaços educacionais as possibilidades das TEI ou as que utilizam as TEI na forma de um pacote fechado, instrumental e acrítico. 
A interação dialética dos aspectos contrários internos, tanto no âmbito da qualidade quanto da quantidade, gera o movimento que tende a alterar o fenômeno na sua totalidade, aproximando-o ou não da forma e do conteúdo das tendências externas.

A partir dos conceitos de autoria e autonomia podemos pensar que o fundamento do fenômeno é o trabalho dos educadores, pois é nele que se evidencia o movimento de luta entre os aspectos contrários na apropriação das TEI. Este fundamento desvela a essência do fenômeno que é o próprio conhecimento, pois a prática social é o critério de verdade na construção e inserção deste conhecimento.

O movimento destas contradições determinará recursivamente a direção do desenvolvimento do fenômeno, ou seja, determinará as possibilidades emancipatórias ou não da inserção das TEI no trabalho dos educadores.

A partir destas considerações, é que venho desenvolvendo a parte empírica de meu estudo, utilizando e pesquisando preferencialmente ambientes, softwares livres e outros meios disponíveis na www, acessáveis através de qualquer sistema operacional e navegador. É meu objetivo, também, intervir nas comunidades pesquisadas de modo a compartilhar estes ideais e o conhecimento que construir nesta investigação.

O projeto zaptlogs utiliza weblogs como ambiente de interação e formação de uma comunidade de pesquisadores que, ao mesmo tempo, aprendem, ensinam e pesquisam, inserindo as TEI no seu trabalho. Está ligado ao objetivo geral de minha proposta de mestrado que é investigar a constituição e o desenvolvimento de comunidades de pesquisadores, identificando e analisando as contradições em movimento neste processo, a fim de contribuir para a construção de alternativas para a formação de educadores autores e autônomos no trabalho com tecnologias educacionais informatizadas. 
Segundo Karel Kosík (1976) a realidade não se mostra imediatamente ao homem. A realidade, no cotidiano, apresenta-se às pessoas como parte sensível e prática de suas atividades. Na teia de relações sociais, as coisas não são normalmente e a priori tomadas como objetos de investigação aos quais cabe analisar e compreender teoricamente. Por isso, muitas vezes as pessoas conhecem ou manejam a realidade, mas não a compreendem. A divisão do trabalho é um fator que coopera para a fragmentação do conhecimento e a visão parcial da realidade imediata e, também, para a aceitação de afirmações que até invertem o sentido das coisas.

Para Kosík (1976), as coisas só podem ser conhecidas por meio de uma atividade. Faz parte deste movimento de compreensão, analisar a atividade por meio da qual um fenômeno pode ser compreendido. Analisar criando esta atividade, que, por sua vez, é um modo de conhecer a realidade, ou maneira como conferimos sentido à coisa.

Vygotsky $(1989,1984)$, compreendeu a importância da categoria da atividade na construção da consciência. Baseando-se em Marx, vê a consciência originada na atividade prática, construída na interação dos seres humanos com o ambiente. Uma consciência que se transforma na medida em que se transforma a atividade humana sensível. Uma relação de homens e mulheres com o mundo que transcende a relação sujeito-objeto, pois os seres humanos fora das condições sócio-econômicas-culturais objetivas da sociedade não têm existência histórica. (BAKHTIN, 2000; VYGOTSKY, 1984)

Investigar a inserção das TEI no trabalho de educadores é investigar a formação do educador no contexto da sociedade atual. Este fenômeno vem chamando a atenção de muitos pesquisadores e sendo tema de investigações que buscam, sob diversas orientações teóricas, conhecer melhor seus diferentes elementos constituintes.

A inserção das TEI no trabalho do educador é um fenômeno amplo e complexo. Nele interligam-se vários elementos, cada um deles passível de tornar-se objeto de pesquisa. Decidi centrar minha investigação no processo de incorporação das TEI aos saberes e ao trabalho do educador em comunidades de educadores pesquisadores. Esta delimitação, por um lado focaliza a investigação num determinado grupo, mas, por outro, tende a aumentar o número de categorias e relações envolvidas. 
Estou buscando conhecer o processo de incorporação das TEI ao trabalho do educador em comunidades de pesquisadores através de uma atividade que desvele as tendências contrárias que habitam o interior deste fenômeno. Nesta atividade, procuro atingir os objetivos propostos e encontrar resposta para as questões norteadoras da investigação. É mediante esta mesma atividade que acredito que os educadores, participantes desta pesquisa, possam transformar as TEI de um conhecimento em si em um conhecimento para si.

A investigação é de natureza qualitativa incluindo alguns aspectos quantitativos, dentro do referencial teórico construído e considerando que existe uma realidade que precisa ser desvelada, conhecida, descrita, interpretada, compreendida, criticada e considerada em seus significados. Considera, também, que esta realidade encontra-se em movimento, um processo sempre em transformação, através da interação dialética de suas contradições.

A participação do pesquisador está incluída como realidade no fenômeno investigado e são consideradas todas as suas implicações. Deste modo, esta proposta de investigação caracteriza-se como pesquisa-ação crítica, pois, segundo Triviños (2003), na América Latina, este tipo de pesquisa assumiu progressivamente características críticas dada a necessidade de transformação das realidades estudadas. Como exemplo, aponto a pesquisa participante de Paulo Freire, no Brasil e a pesquisa-ação de Fals Borda, na Colômbia, ambas de cunho crítico e transformador, baseadas em fundamentos teóricos metodológicos semelhantes.

\section{Etapas previstas para a investigação e seu estado atual}

1 - O projeto foi apresentado aos educadores ligados ao $\mathrm{TRAMSE}^{8}$, com o intuito de verificar quais os potenciais participantes. Dentre os interessados foram escolhidos, intencionalmente, um grupo inicial de dez educadores que estão trabalhando ou preparando-se para trabalhar em projetos de pesquisa em educação e que necessitam aprofundar sua relação com as TEI.

Este grupo participa na elaboração do plano de atividades que inclui o desenvolvimento de projetos dos educadores, por meio do trabalho cooperativo virtual/presencial, com a mediação das TEI. No desenvolvimento dos projetos e na 
medida das necessidades, a aproximação aos meios possibilitados pelas TEI será implementada.

Utilizando um questionário com perguntas abertas e fechadas, procurei levantar informações gerais dos participantes sobre o nível de conhecimento e envolvimento que tem com as TEI, suas expectativas em relação ao projeto e suas intenções de pesquisa.

2 - Durante todas as fases do projeto prossigo na construção teórica e na revisão de literatura que dão fundamento a esta investigação. Com este movimento, dentro de sua circularidade aberta, pretendo realimentar a construção teórica da investigação.

O ambiente zaptlogs, bem como os outros ambientes do projeto, inclusive o que registra as minhas reflexões como pesquisadora, encontram-se acessíveis a qualquer pessoa que tenha interesse em conhecer, acompanhar e colaborar com a investigação, cooperando, assim, para a criação de um novo estatuto para a pesquisa efetuada nas universidades.

3 - Está sendo construído, em conjunto com o grupo, baseado nos dados levantados na etapa anterior, um plano de trabalho que inclua os principais objetivos e conteúdos relativos as TEI.

As atividades de interação incluem a comunicação por correio eletrônico, lista de discussão e a participação num weblog de grupo, o [zaptlogs], construído inicialmente pelo investigador a partir de recursos disponíveis gratuitamente na www. Este ambiente inicial poderá sofrer modificações pelo grupo durante o projeto, na medida de suas necessidades e de suas possibilidades de intervenção.

4 - Para atender os objetivos desta investigação, propus ao grupo que, a partir do ambiente comunitário, criassem, cooperativamente, ambientes virtuais ou conjuntos de instrumentos que dêem suporte aos projetos individuais ou coletivos. Estes ambientes estão em fase inicial de criação.

5 - Os conteúdos técnicos e/ou pedagógicos referentes as TEI vem sendo tema de oficinas específicas, realizadas no laboratório de informática. 
6 - As atividades são objeto de avaliação permanente, por todos os envolvidos no estudo, sendo prevista uma avaliação ao final do projeto, conforme o cronograma previsto para esta investigação.

7 - A coleta de dados acontece desde o início do projeto. Os dados são coletados durante as observações participantes, na interação em reuniões e oficinas presenciais ou virtuais, nos projetos cooperativos e nas entrevistas com os sujeitos da pesquisa.

Os instrumentos para coleta de informações são o diário de campo de observação da comunidade virtual e dos weblogs individuais e grupais, os relatórios de oficinas e a gravação de entrevistas semi-estruturadas com os sujeitos participantes.

8 - Tratamento dos dados coletados.

A medida em que as informações são colhidas, de imediato entram no processo de organização e classificação. As informações contidas no diário de campo e nos arquivos dos ambientes estão sendo analisadas de modo à, num primeiro momento, localizar as categorias empíricas relevantes ao estudo e, num segundo momento, sistematizar as categorias de modo a concentrá-las em aspectos que reflitam a fundamentação teórica do projeto.

Farei a transcrição e a análise das entrevistas mediante o mesmo processo anterior, sendo agrupadas, se possível, segundo as mesmas categorias já estabelecidas. Nos dois casos, escolherei os dados conforme sejam significativos dentro da temática de investigação.

Analisarei os dados coletados e sistematizados no âmbito da teoria, procurando descrever, explicar, interpretar e compreender o fenômeno estudado, tanto de forma sincrônica quanto de forma diacrônica.

O tratamento dos dados coletados procurará extrair os aspectos relevantes das análises anteriores, comparando-os, dentro da fundamentação teórica, aos objetivos desta investigação e verificando as possibilidades de resposta as questões de pesquisa, num processo dialético de progressiva concreção. 
9 - O relatório vem sendo redigido durante a investigação, incorporando de forma recursiva o próprio processo investigativo e os resultados e conclusões provenientes da construção teórica e do tratamento dos dados coletados.

\section{Cronograma}

\begin{tabular}{|c|c|c|c|c|c|c|c|c|c|c|c|}
\hline \multirow{2}{*}{ Ativ. } & \multicolumn{7}{|c|}{2003} & \multicolumn{4}{|c|}{2004} \\
\hline & Jun & Jul & Ago & Set & Out & Nov & Dez & Jan & Fev & Mar & Abr \\
\hline 1 & $\mathrm{x}$ & & & & & & & & & & \\
\hline 2 & $\mathrm{X}$ & $\mathrm{X}$ & $\mathrm{X}$ & $\mathrm{X}$ & $\mathrm{X}$ & $\mathrm{X}$ & $\mathrm{X}$ & $\mathrm{X}$ & $\mathrm{X}$ & $\mathrm{X}$ & $\mathrm{X}$ \\
\hline 3 & $\mathrm{x}$ & & & & & & & & & & \\
\hline 4 & & & $\mathrm{X}$ & $\mathrm{X}$ & $\mathrm{X}$ & $\mathrm{X}$ & $\mathrm{X}$ & & & & \\
\hline 5 & $\mathrm{X}$ & $\mathrm{X}$ & $\mathrm{X}$ & $\mathrm{x}$ & $\mathrm{X}$ & $\mathrm{x}$ & $\mathrm{X}$ & & & & \\
\hline 6 & $\mathrm{x}$ & $\mathrm{x}$ & $\mathrm{x}$ & $\mathrm{x}$ & $\mathrm{x}$ & $\mathrm{x}$ & $\mathrm{x}$ & & & & \\
\hline 7 & $\mathrm{x}$ & $\mathrm{X}$ & $\mathrm{X}$ & $\mathrm{x}$ & $\mathrm{x}$ & $\mathrm{X}$ & $\mathrm{X}$ & & & & \\
\hline 8 & & $\mathrm{x}$ & $\mathrm{x}$ & $\mathrm{x}$ & $\mathrm{x}$ & $\mathrm{x}$ & $\mathrm{x}$ & $\mathrm{X}$ & $\mathrm{x}$ & & \\
\hline 9 & $\mathrm{X}$ & $\mathrm{x}$ & $\mathrm{x}$ & $\mathrm{x}$ & $\mathrm{x}$ & $\mathrm{x}$ & $\mathrm{x}$ & $\mathrm{x}$ & $\mathrm{x}$ & $\mathrm{X}$ & $\mathrm{x}$ \\
\hline
\end{tabular}

\section{Considerações finais}

É praticamente impossível pensar em trajetórias determinadas ou finalizações previstas para pesquisas em andamento, ainda mais quando estas concernem às tecnologias informatizadas.

A relativa novidade dos temas e o acelerado desenvolvimento de tudo que os cercam não nos permitem fechamentos. Quando muito, podemos relacionar as tendências e pensar alguns movimentos.

Penso que muito ainda ouviremos sobre os weblogs e suas possibilidades na educação e na pesquisa. Tanto do ponto de vista dos educadores quanto do ponto de vista de outras áreas e de seu desenvolvimento como tecnologia.

Neste aspecto, saliento a convergência dos weblogs, bem como a de todas as tecnologias informatizadas, com as tecnologias móveis e sem-fio. Já é realidade a 
transmissão e publicação de texto, imagem e som por meio de telefones celulares, com ou sem a mediação do computador. Isso, que se constitui numa revolução dentro da comunicação e do jornalismo, certamente pode ter suas perspectivas antevistas em relação aos meios educacionais.

Aponto, também, o papel que penso que será determinante dos protocolos como o RSS e as tecnologias relacionadas na difusão e socialização da informação e dos trabalhos de pesquisa.

Este artigo teve como objetivo apresentar um dos primeiros estudos, talvez o primeiro, que está sendo feito sobre os weblogs na educação no Brasil. A novidade e pioneirismo do estudo residem não apenas no tema, mas também na forma aberta como está sendo realizada a pesquisa que, de certa forma, subverte a modalidade acadêmica de pesquisa.

Neste sentido, este artigo procura, também, dar uma visão geral sobre a tecnologia dos weblogs e suas possibilidades, de modo a compartilhar este conhecimento com os colegas pesquisadores e abrir espaço à cooperação. Penso que, de acordo com o cronograma proposto, na época de apresentação deste tema já teremos alguns resultados a compartilhar.

\section{Notas do Texto}

${ }^{1}$ Um exemplo de weblog é o próprio ambiente deste projeto, que pode ser visualizado em http://planeta.terra.com.br/educacao/Gutierrez/blogs/zapt/

${ }^{2}$ Como este artigo destina-se a educadores e pesquisadores já familiarizados com a terminologia utilizada na internet e das tecnologias da informação e da comunicação, não colocarei explicações adicionais sobre os termos mais comuns, mantendo a grafia mais encontrada.

${ }^{3}$ Os endereços de todos os sites citados estão nas referências.

${ }^{4}$ blogueiro vem de bloggers e significa aquele que publica um weblog.

${ }^{5}$ rssficar é a forma como os blogueiros se referem ao processo de codificar a página num formato rss.

${ }^{6}$ um webring é uma rede de páginas interligadas que se referem mutuamente, geralmente versando sobre o mesmo tema.

${ }^{7}$ zaptlogs tem este nome porque é um subprojeto do projeto integrado ZAPT que, por sua vez, quer dizer Zona de Apoio e Pesquisa em Tecnologia. O ZAPT é um projeto do

${ }^{8}$ TRAMSE - Núcleo de Estudos, Experiências e Pesquisa em Trabalho, Movimentos Sociais e Educação - do PPGEdu da UFRGS.

\section{Referências}


24 HOURS OF DEMOCRACY homepage Acton: Userland Software, Inc, 1997. Disponível em <http://www.scripting.com/twentyFour/>, acesso em junho de 2003.

AXT, Margarete. Tecnologia na educação, tecnologia para a educação: um texto em construção. Informática na Educação: teoria \& prática, Porto Alegre: UFRGS, Vol. 3, n.1 (set 2000). p. 51-62.

BAKHTIN, Mikhail. Estética da criação verbal. São Paulo: Martins Fontes, 2000. 421 p.

BLOGCHALK homepage Belo Horizonte: Daniel Pádua, 2003. Disponível em

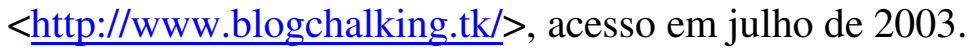

BLOGGER homepage São Francisco, CA: Pyra Labs, 2003. Disponível em $<$ http://www.blogger.com/>, acesso em julho de 2003.

BLOGGER.BR homepage São Paulo: Globo.com, 2003. Disponível em $<$ http://comentario.globo.com/index.jsp>, acesso em julho de 2003.

BLOGCOUNT homepage Oakland, CA: Philip Wolff, 2003. Disponível em

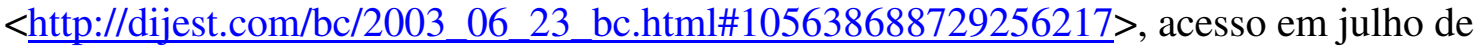
2003.

FREIRE, Paulo. Pedagogia da autonomia. 25ed. Rio de Janeiro: Paz e Terra, 2002. $165 \mathrm{p}$.

GEO URL ICBM ADRESS SERVER homepage Pittsburgh, PA: Joshua Schachter, 2003. Disponível em <http://geourl.org/>, acesso em julho de 2003.

KÓSIK, Karel. Dialética do concreto. $2^{\text {a }}$ ed. Rio de Janeiro: Paz e Terra, 1976.250p.

NEWS. weblog In: 24 HOURS OF DEMOCRACY homepage Acton: Userland Software, Inc, 1997. Disponível em <http://www.scripting.com/twentyFour/news.html> , acesso em junho de 2003.

NEWSDESK. In: Wildgrape. homepage s/local: David Peckham, 2003 Disponível em $<$ http://www.wildgrape.net/>, acesso em julho de 2003.

PAPERT, Seymour. Logo, Computadores e Educação. São Paulo: Brasiliense, 1985. $253 p$. 
SCRIPTING NEWS weblog. Acton: UserLand Software, Inc, 2003. Disponível em $<$ http://www.scripting.com/>, acesso em junho de 2003.

THE WORLD AS A BLOG homepage. San Francisco, CA: Mikel Maron, 2003. Disponível em <http://brainoff.com/geoblog/>, acesso em julho de 2003.

TRIVIÑOS, Augusto N. S. ; BURIGO, Carla ; COLAO, Magda. A formação do educador como pesquisador. In: TRIVIÑOS, Augusto N. S. ; OYARZABAL, Graziela M.; ORTH, Miguel ; GUTIERREZ, Suzana (org). A formação do educador como pesquisador no Mercosul - Cone Sul. Porto Alegre, Editora da UFRGS, 2003, p.1760 .

VYGOTSKY, Lev Pensamento e linguagem. São Paulo: Martins Fontes, 1989.135 p.

VYGOTSKY, Lev A formação social da mente : o desenvolvimento dos processos psicológicos superiores. São Paulo: Martins Fontes, 1984. 168 p.

W.BLOGGAR homepage Recife: Marcelo Cabral, 2003. Disponível em

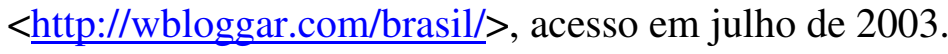

ZAPTLOGS weblog Porto Alegre: Suzana Gutierrez, 2003. Disponível em $<$ http://planeta.terra.com.br/educacao/Gutierrez/blogs/zapt/>, acesso em julho de 2003. 
